a true psychotomimetic compound in the sense that LSD, mescaline and psilocybin are. In spite of this, constant reference has been made to "psychotic episodes" produced by and the "psychotomimetic properties" of bufotenin (Nature, 216, 538; 1967). Then, by innuendo, the presence of bufotenin is reported in the urine of chronic schizophrenics (Inter. J. Neuropsychiat., 3, 226; 1967) and of mentally defective patients as well ( $J$. Neuropsychiat., $5,14 ; 1963$; and Nature, 216,$490 ; 1967)$. It is well to remomber, however, that bufotenin is a normal constituent of urine since Gross and Franzen (Biochem. Zschr., 340, 403; 1964 ) found it in amounts of $62 \cdot 75 \pm 7.21 \mu \mathrm{g} / 24 \mathrm{~h}$ in fifty healthy individuals based on a selective fluorimetric procedure for the detection of the compound in blood and urine. In chronic schizophrenies, however, the amount of daily bufotenin and N-methyltryptamine excreted "should be less than $10 \mu \mathrm{g}$, if they occurred" (Nature, 216, 1110; 1967).

\section{Yours sincerely,}

\section{Roland Fischer}

Department of Psychiatry,

College of Medicine,

The Ohio State University,

Columbus, Ohio 43210.

\section{New Materials Make Their Mark}

Sir,-The author of "New Materials Make Their Mark" (Nature, 219,$818 ; 1968$ ) is, I am sure quite unintentionally, a little misleading.

The process for producing carbon fibre from polyacrylonitrile cannot be a commercial secret since your author provides an accurate set of process conditions.

The technology is not an original discovery by three scientists at the Royal Aircraft establishment, as I am sure Watt et al. will have informed you by now. The technique was first published by Shindo ${ }^{1}$ in 1961. Patent priority is held by the Tokai Denkyoku Seizo Kabushiki Kaisha Corporation ${ }^{2}$ of Japan, who filed in 1960. RollsRoyce have filed several patent applications for their original research in the fundamentals of carbon fibre production based on work reported in outline in Nature $^{3}$.

$$
\text { Yours faithfully, }
$$

\section{A. E. Standage}

University of Dayton,

Dayton, Ohio 45409.

${ }^{1}$ Shindo, A., Rep. Gov. Ind. Res. Inst., Ooka, Japan, No. 317, December 1961. ${ }^{2}$ Application No. 36145 (Japan), August 25, 1960. Complete Specification No. $29270 / 61$ published (United Kingdom) November 28, 1962.

${ }^{3}$ Nature,211, 169 (1966).

\section{Parapsychology}

Sir.-May I raise a few points concerning the article "Identification of Concealed Randomized Objects through Acquired Response Habits of Stimulus and Word Association" (Nature, 220, 89; 1968) ?

The covers are described as "opaque". No mention is made of other characteristics or of the material. It is not clear how the experimenters identified the covers (were the numbers marked on them?), but obviously they did; therefore there is nothing very unusual in the subject's being able to do so in series 1,2 and 3 .

The subject might have relied on touch in the other series, including perhaps series 11-18. From series 4 onwards, at least one experimenter knew which cover was contained in any particular jacket. Thus a clue might have been left, unwittingly, when the cover was placed in the jacket (for example, the cover might havo been inserted slightly to one side). Or, again, a cluo might have been given by an experimenter while the subject was guessing (for example, by minute facial or eye movement). Was it always the same experimenter who placed the covers in the jackets? It might also be worth examining the results in more detail to see if the association took a number of initial trials to be established.

Since at least one experimenter knew the location of the covers, the possibility of telepathy exists. A series should have been conducted with the covers and jackets concealed from the subject (for example, behind a sereen or in another room) and another with the knowing experimenter also out of sight.

Finally, as a control, some trials with no cards and/or plain "dummy" cards inside the covers and some trials with no covers and/or "dummy" covers inside the jackets should have been performed. (The subject might have shown a preference for. certain jackets.)

$$
\text { Yours faithfully, }
$$

E. J. FARGE

69 South Hill Park,

\section{London NW3.}

\section{Ethics and Abortion}

Sir,--Your report on the Institute of Biology Symposium on "Biology and Ethics" (Nature, 220, 11 ; 1968) is not quite correct in saying that "No member of the symposium chose to reply to a speaker who held that the right and responsibility for deciding on an abortion rested solely with the pregnant woman herself".

In fact. I attempted to answer this myself from the floor, by pointing out that it begged the whole question of whether the child does have any rights of its own at any stage before it is born. If it does not, then, of course, the decision can be left to the mother: it raises no more of an ethical problem than killing off an unwanted puppy.

But if the child is to be allowed any rights to its life at all, which the meeting appeared ready to concede at any rate towards the end of pregnancy (the increasing reluctance to abort after the third month, mentioned by Dr Potts, does not depend solely on the risk to the mother), then unless we are prepared to ignore these rights altogether, it cannot be left to the mother alone to act as judge in her own cause, between her interests and those of the child.

It was also argued at this meeting that a woman must be allowed the right to do anything she pleases with her own body. That is true enough, but unfortunately more than the mother's own body is involved in terminating a pregnancy. Whatever one may feel to the contrary, it is an indisputable biological fact that the embryo is a separate living organism right from the start, wholly dependent and in a sense even parasitic on its mother, but no more a part of her own body than a tapeworm would be. But it is a separate living human individual, and is going to grow into a man if it is not to be killed. Yours sincerely,

$$
\text { C. B. Goonhart }
$$

Gonville and Caius College,

Cambridge.

\section{Announcements}

Dr J. W. Gornforth, co-director of Shell Oil Company's Milstead Laboratory in Kent, has been awarded the $\$ 2,000$ Ernest Guenther Award by the American Chemical Society. The award was given in recognition of his work on terpenoids.

Mr P. W. Mummery, at present deputy director, Technical Operations, Reactor Group, has been appointed director of the Dounreay Experimental Reactor Establishment, Reactor Group, in succession to Mr R. W. Matthews.

Professor W. G. Wellington, professor of ecology in the University of Toronto, has been awarded the gold medal of the Entomological Society of Canada in recognition of his contribution to entomology in Canada. 